\title{
An Application of Systemic Functional Grammar on Rilke's poem 'A Walk'.
}

\section{Mubarak Ali Lashari ${ }^{1}$ and Faraz Ali Bughio ${ }^{2}$}

${ }^{1} \mathrm{PhD}$ Scholar at Department of English, International Islamic University, Islamabad, Pakistan.

${ }^{2}$ Assistant Professor at Institute of English Language and Literature, University of Sindh, Jamshoro.

\begin{abstract}
The intention, this study was launched with, was to explore the applicability of the Systemic Functional Grammar, the linguistic development promoted by famous linguist M.A. K. Halliday. The theory establishes the view of functionality of linguistic phenomena in the pieces of literature. The study in hand is aimed to find the functional elements in Rainer Maria Rilke's poem 'A Walk'. The poem was analyzed into three major functional methods of the theory including Ideational, Interpersonal and Textual analysis. In the first category, the transitivity patterns and the clauses having active and passive voices were analysed. In the second, the interpersonal elements; having the persons involving in the process and showing relationship with each other were seen. And finally, the textual meaning and the sense emerging from all the above findings were discussed. It further sought the theme of the poem and the basic functional idea of the poetic expression. And in the final stage the emanating message of the poem was discussed in the conclusion.
\end{abstract}

Keywords: systemic functional grammar; ideational; experiential; transitivity; interpersonal; textual; linguistic functions.

\section{Council for Innovative Research}

Peer Review Research Publishing System

Journal: Journal of Advances in Linguistics

\author{
Vol 4, No. 1 \\ editor@cirjal.com \\ www.cirjal.com, www.cirworld.com
}




\section{Introduction}

Systemic Functional Grammar or SFG or Functional Grammar FG or also called Systemic Functional Linguistics, is well-recognized contribution in the study of language with regard to language-context and language-function. The person who propounded this grammatical theory is Austrian linguist Michael Alexander Kirkwood Halliday, well-known as M.A.K Halliday. He after analyzing different linguist theories and systems reached to the idea of exploring the function of language playing in the discourse or literary expressions. In theoretical perspective SFG consists of two components: SYSTEMIC GRAMMAR and FUNCTIONAL GRAMMAR.

Both are foremost basis of the grammatical and linguistic theory.

Systemic grammar aims to explain the internal relations in language as a system network, or meaning potential. And this network consists of subsystems from which language users make choices. Functional grammar aims to reveal that language is a means of social interaction, based on the position that language system and the forms that make it up are inescapably determined by the uses or functions which they serve.

(Hu Zhuanglin, 1988: 307).

Furthermore, Halliday thinks that stylistic analysis should be carried out through three logically ordered phases: Analysis, Interpretation and Evaluation (Wang, 2010:255). In continuity of the above phases he takes this analysis to more abstract and well-coded linguistic/grammatical analysis or functions-meta-functions that is said to be the lying intrinsic in every language. Those intrinsic functions of language are called as ideational function, the interpersonal function and the textual function.

\section{a. Ideational Function}

The first function Halliday points out is the ideational function. What is ideational function?

It is through this function that the speaker or writer embodies in language his experience of the phenomena of the real world; and this includes his experience of the internal world of his own consciousness: his reactions, cognitions, and perceptions, and also his linguistic acts of speaking and understanding (Halliday, 1971: 332)

In other words, this function is to convey new information, to communicate a content that is unknown to the hearer. It reflects the events and experience in both objective and subjective worlds.

The ideational function mainly consists of "transitivity" and "voice". Hu Zhuanglin, a Chinese linguist, points out: "This function not only specifies the available options in meaning but also determines the nature of their structural realizations" (Hu Zhuanglin, 1988: 312). For Example, Kitty flies a kite can be analyzed as: the Actor is Kitty, the process is Material and the Goal is a kite. The Actor, Process, Goal, and their subcategories reflect our understanding of phenomena that come within our experience.

The ideational function is mainly represented by the transitivity system in grammar. In this system the meaningful grammatical unit is clause which expresses what is happening, what is being done, what's felt and what the state is and so on (Yumin, 2007). The transitivity system includes six processes: material process, mental process, relational process, behavioral process, verbal process and existential process.

Material processes are those in which something is done. These processes are expressed by an action verb (e.g. eat, go, give), an Actor (logical subject) and the Goal of the action (logical direct object, usually a noun or a pronoun). (Hu Zhuanglin, 1988) e.g. Marry is eating a banana.

Mental processes express such mental phenomena as "perception" (see, look), "reaction" (like, please) and "cognition" (know, believe, convince). A mental process involves two participants, Sensor and Phenomenon. (Hu Zhuanglin, 1988) e.g. Tom likes chocolate.

Relational processes can be classified into two types: Attributive and Identifying. The former expresses what attributes a certain object has, or what type it belongs to, for example, The temperature is high. The latter expresses the identical properties of two entities. For example, Lily is a girl; The girl is Lily. (Hu Zhuanglin, 1988)

Verbal processes are those of exchanging information. Commonly used verbs are say, tell, talk, praise, boast, describe, etc. In these processes the main participants are Sayer, Receiver and Verbiage.

Behavioral processes refer to physiological and psychological behavior such as breathing, coughing, smiling, laughing, crying, staring, and dreaming, etc. Generally there is only one participant-Behaver, which is often a human. This kind of processes is much like the mental process. Behavioral process may sometimes be hardly distinguished from a material process that has only one participant. This depends on whether the activity concerned is physiological or psychological. When Behavioral process has two participants, we may take it as material process, for example, His father beat the disobedient boy. (Hu Zhuanglin, 1988)

Existential processes represent that something exists or happens. In every existential process, there is an Existent. For Example,

There is a girl in the garden.

Does ghost exist on earth? 
Here comes a bus.

\section{b. Interpersonal Function}

In the second place, language serves as interpersonal function. As Halliday observed,

The speaker is using language as the means of his own intrusion into the speech event: the expression of his comments, attitudes and evaluations, and also of the relationship that he sets up between himself and the listener-in particular, the communication role that he adopts of informing, questioning, greeting, persuading, and the like. (Halliday, 1971:333)

Hu Zhuanglin (1988:313) points out: "The interpersonal function embodies all uses of language to express social and personal relations. This includes the various ways the speaker enters a speech situation and performs a speech act."

Modality and Mood are often used to express the interpersonal function. Mood shows what role the speaker selects in the speech situation and what role he assigns to the addressee. If the speaker selects the imperative mood, he assumes the role of one giving commands and puts the addressee in the role of one expected to obey orders. For example, Pass me the book. (Hu Zhuanglin, 1988)

Modality refers to the intermediate ranges between the extreme positive and the extreme negative. It is one of the most important systems in social communication. On the one hand, it can objectively express the speaker's judgment toward the topic. On the other hand, it can show the social role relationship, scale of formality and power relationship. In English, except modal verbs, modal adverbs, adjectives, there are also personal pronouns, notional verbs, tense, direct and indirect speeches to express the modalization.

\section{c. Textual Function}

The third role of language is called textual function. Halliday described, "Language makes links between itself and the situation; and discourse becomes possible because the speaker or writer can produce a text and the listener or reader can recognize one" (Halliday, 1971:334). According to Hu Zhanglin,

The textual function refers to the fact that language has mechanisms to make any stretch of spoken or written discourse into a coherent and unified text and make a living passage different from a random list of sentences. Although two sentences may have exactly the same ideational and interpersonal functions, they may be different in terms of textual coherence. (Hu Zhuanglin, 1988: 315)

The textual function fulfils the requirement that language should be operationally relevant, having texture in a real context of situation that distinguishes a living passage from a mere entry in a grammar book or a dictionary. It provides the remaining strands of meaning potential to be woven into the fabric of linguistic structure. Information can be clearly expressed in a discourse. It can also be implicated between the lines. Therefore, all discourses are unities of explicit and implicit message. (Halliday, 1971)

It is because language serves as a generalized ideational function, we are able to use it for all the specific purposes and types of context which involve the communication of experience. Because it serves a generalized interpersonal function, we are able to use it for the specific forms of personal expression and social interaction. And a prerequisite to its effective operation under both these headings what we have referred to as the textual function, whereby language becomes text, is related to itself and to its contexts of use. Without the textual component of meaning, we should be unable to make any use of language at all (Hu Zhuanglin, 1988).

\section{Introduction to the poet}

Rainer Maria Rilke (1875- 1926), the Bohemian-Austrian poet is considered most significant poet and art critic in German language in modern age. He is considered as the poet of depicting the images of different combinations. He, with regard to the themes in his poetry, is said to be the poetic figure of transition as connecting the traditional concepts of $19^{\text {th }}$ century with the modernist concepts. He wrote both in verse and the also fine lyrical poems. He was soon well recognized in the younger peoples regarding changes according to the modernist development. His poem "A Walk" is a fine mental picture in poetic version.

\section{Introduction and Analysis of the Poem}

This poem is a finely depicted picture of his vision and imagination. In it the poet seems to be walking towards the hill in some deep thoughts but his vision and his thinking/imagination reaches the hill far ahead of the physical distance covered by his feet. Not only the vision of the poet is faster but the personification of the hill: the feelings of the hill and its inner light grasps his own soul and consequentially transforms it spiritually much before his own inner luminescence reaches it. Here the hill seems to have human characteristics of making gesture of kinship with him in response to his own gesture. All that the poet is feeling is the tender wind, which is touching his face while going there.

In this poem, sensory impressions are used to create beautiful images in description like paintings. To express poets own vision the hill is personified featuring to it human persona such as "charges", gesture", "grasping". A beautiful combination of the visual and perceptible elements recreates the situation in which the poet re-experiences the intensity of the moments as "emotion recollected in tranquility".

\section{A Walk}

My eyes already touch the sunny hill.

going far ahead of the road I have begun. 
So we are grasped by what we cannot grasp; it has ITS inner light, even from a distance-

and CHARGES us, even if we do not reach it, into something else, which, hardly sensing it, we already are; a gesture waves us on answering our own wave...

but what we feel is the wind in our faces.

\section{Ideational Function}

In ideational function the language is carrying the message of embodying writer and the reader and speaker and the listener. It does so firstly be sentence patterns and transitivity. In sentence patterns the clauses are observed and in transitivity the processes (verbs patterns) are seen. Following tables are showing the transitivity patterns in the poem.

Table 1

OVERVIEW OF PROCESS TYPES

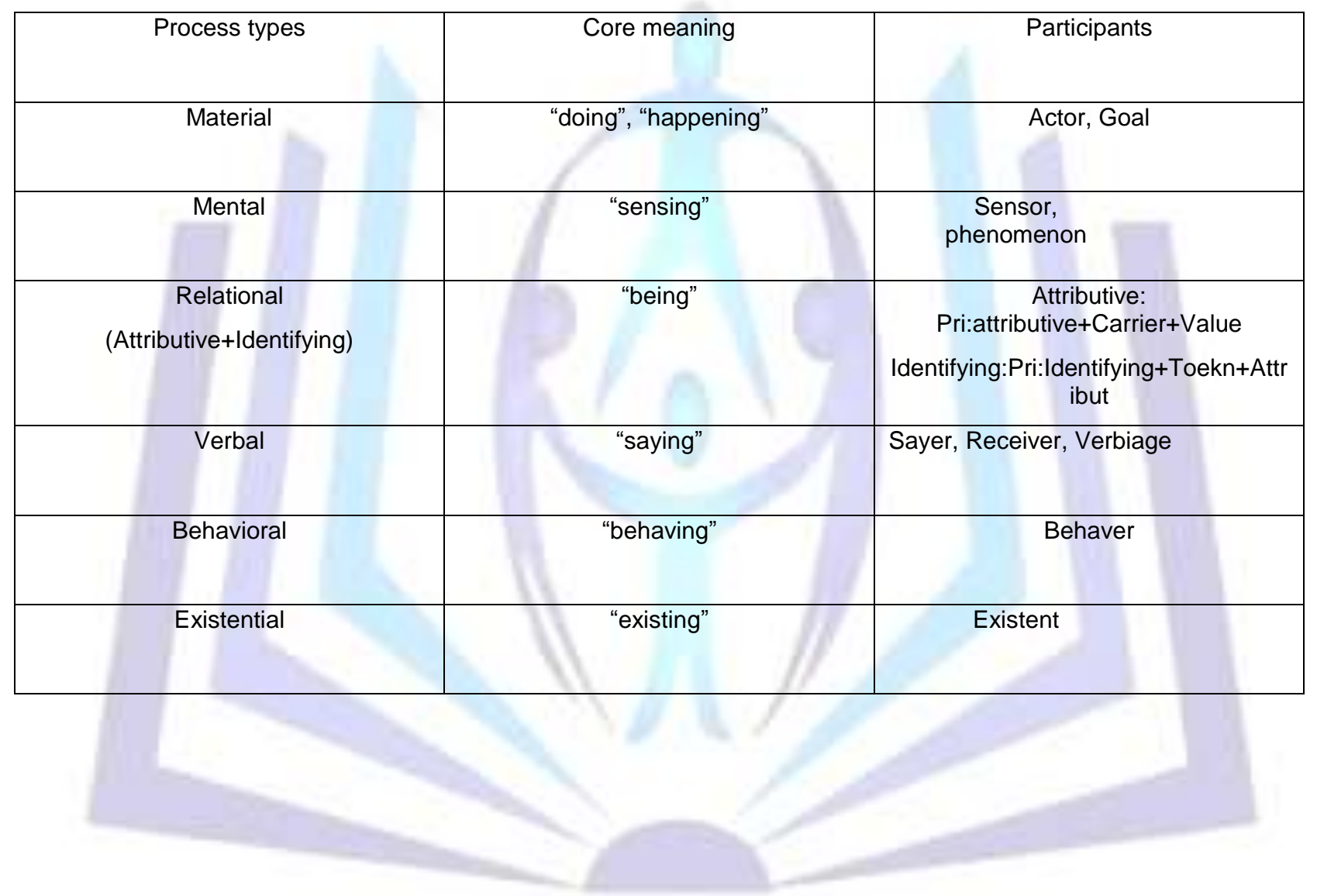


Table 2

Transitivity Pattern in the Poem

\begin{tabular}{|c|c|c|c|}
\hline Process & Process words & Number & Percentage \\
\hline Material & $\begin{array}{c}\text { "Touch", "begun", } \\
\text { "charges", "reach" and } \\
\text { "waves" }\end{array}$ & 5 & $41.66 \%$ \\
\hline Mental & $\begin{array}{l}\text { "grasped", "grasp", } \\
\text { "sensing" and "feel" }\end{array}$ & 4 & $33.33 \%$ \\
\hline Relational & --- & --- & \\
\hline Verbal & ----- & ---- & \\
\hline Behavioral & ------ & ---- & \\
\hline Existential & "has", "are" and "is" & 3 & $25 \%$ \\
\hline Total & & 12 & $100 \%$ \\
\hline
\end{tabular}

From table 2 we can notice that material process is used most in the poem to show the action that consists of around 41 percent. Such as "Eyes touch the hill, I have begun, (it) charges us, we reach it, a gesture waves us." As it is well-known that material process shows "doing" so the description of such things in the poem reveals that under discussion thing/object or agent is active to do and leave some effects on the goals.

On the other hand second most used process is mental that consists of 33 percent. Such as "we are grasped, we cannot grasp, we feel. In poetry this kind description is vital to have emotional or sentimental effects especially in romanticist concept and flow.

Then there are existential processes that are 3 and has 25 percentage, such as "it has light, we already are, what (we feel) is the wind in our faces".

And finally relational, verbal, and behavioral processes are not found in the poem whereas the process "has" can share the idea of relational with existential process.

\section{Interpersonal Function}

This category of grammatical analysis of the systemic functional grammar is to analyse the interacting elements in the text. It approach is entwined with the discourse analysis and its speech act theory. "Halliday approaches the grammar of interaction from semantics perspective. He points out that whenever we use language to interact, one of the things we are doing with it is establishing a relationship between us" (Eggins, 1994). In that perspective following is the analysis of the relationship of the factors.

Table 3

\section{Personal Pronouns}

\begin{tabular}{|l|c|c|c|}
\hline Personal Pronoun types & Personal Pronouns & Total number & Percentage \\
\hline First person & "l", "we", "we", "we", "we", we" & 6 & $35.29 \%$ \\
\hline Third person & "it", "it", "it" & 3 & $17.64 \%$ \\
\hline Possessive & "my" (eyes) "its", "our", "our" & 4 & $23.52 \%$ \\
\hline Accusative & "us", "it", "it", "us" & 4 & $23.52 \%$ \\
\hline Total & & 17 & $100 \%$ \\
\hline
\end{tabular}


From the table 3, it can be observed the participants in the poem are mostly "first person pronouns" or "third person pronouns." It is because the poet embodies the readers with him and considers the readers as him or considers himself as the readers. Thus the use of first person pronoun in its cases like possessive 23.52 percent in which three possessives are related to first person pronouns as, "my", "our" and "our" while "its" is related to third person pronoun and accusative case 23.52 percent in which two items are accusatives of first person like "us" and "us" and two items are accusatives of third person pronoun like "it" and "it".

From the context of the poem the reader and poem or poet relationship is expressed with subjective mode of expression. It is that area which distinguishes the poetry or piece of literature from ordinary descriptive writing. It is obvious from the poem that first person is used in abundance and third person pronoun is given not for reader-writer gap but here third is used to describe the things or phenomena that are same from the readers and the poet. And there is no second person to whom poet may address or tell something him as second person as considering it as separate entity from him. The subjective type of poetry giving vent to his feelings is closely associated with the romantic poetry and poets; thus we can say from the standpoint of abundant use of first person pronoun that this poem is subjective rather than objective or descriptive type of poetry.

\section{Textual Function}

The textual function is aimed to the realization that the language has in a way of coherent mechanism, written or spoken discourse, rather that random selection of sentences. It also makes the written or spoken discourse as living piece of writing and a unified text that offers logic and thoughtful. In it the sentence structure or specifically "theme" and "rheme" is analyzed in order to know that what is said to whom.

From this point of view it can be seen that poem is mostly about the objects which are doer or described rather that the observer or the poet who is walking over there such as;

(my) eyes (already) touch the sunny hill (going far ahead of the road I have begun.)

(By what) we are grasped

We cannot grasp

It (hill) has its inner light even from a distance, and charges us,

(Even if) we do not reach it.

From above few examples of theme/rheme description (in which bold words are theme and the italics are rheme) we can see that the it is very subjective poem in which doers or action oriented things are objects like eyes, hill, by what we are grasped rather than we can grasp that is said to be an adoration of nature like romantic poets. It can be seen that when subject/theme is "we" regarding observer/reader/poet it is unable to do anything and is helpless before the fascinating things of the nature like we cannot grasp, we are grasped or it charges us even if we do not reach it. Before doing any action the reader or poet is already done by the object described in the poem.

Furthermore the poem is coherently weaved with cohesive words like "so", "and", "even if", "which" and "but". These words join the ideas and share the structure of the poem in an organic way to make it as one whole.

\section{Conclusion}

To conclude on the basis of above analysis it can be said that the poet is so captivated with nature and objects of the nature or nature observing organs (like eyes) that he becomes unable to perform any action. Next it is seen that there is personification of the natural objects like hill that acts. It is described as the human or living objects that is acting like grasping, charging, answering etc. and possesses humanly characters. In on the one hand is well use of poetic device and the romantic expression and adoration of the natural objects on the other. Furthermore there is no use of modality or model auxiliaries also shows the poet's bent of mind to be absorbed in the subjectivity going beyond the moderate expression or grey area in the subjective or objective expressions.

\section{References}

Eggins, S. (1994). An Introduction to Systemic Functional Linguistics, London: Pinter Publishers.

Halliday, M. A. K. (1979). Linguistic function and literary style: an inquiry into the language of William Golding's The Inheritors. In Linguistic Studies of Text and Discourse. ed. Jonathan J.Webster. 88-125. Peking: Peking University Press.

Hu Zhuanglin.(1988). A Course of Linguistics. Peking: Peking University Press.

Wang, J. (2010). A Critical Discourse Analysis of Barrack Osama's Speeches. Journal of Language Teaching and Research, Vol. 1, No. 3, pp. 254-261, ACADEMY PUBLISHER Manufactured in Finland.

Yumin, C. (2007). An Analysis of Style Features of Inaugural Speeches Given by American Presidents Based on the Functional Theory of Han Lide. From the thesis of a master. Tai Yuan Science University. 


\section{Authors' biography:}

Mubarak Ali Lashari is PhD Scholar at Department of English, International Islamic University, Islamabad. He earned his M.Phil from IIUI in 2010. He is author of 2 books on Postmodernism, Postcolonialism and Literary Theory. Currently, he is working as faculty member of English linguistics at Institute of English Language and Literature, University of Sindh, Jamshoro.

Faraz Ali Bughio He is teaching as Assistant Professor at Institute of English Language and Literature, University of Sindh, Jamshoro. He completed his PhD in 2013 from UK. 